\title{
Concomitant Use of High-dose Methotrexate and Glycyrrhizin Affects Pharmacokinetics of Methotrexate, Resulting in Hepatic Toxicity
}

\author{
KENTARO ABE ${ }^{1,2}$, TSUKASA HIGURASHI ${ }^{1}$, MIO TAKAHASHI ${ }^{1}$, AYAKO MAEDA-MINAMI ${ }^{1}$ \\ YOHEI KAWANO ${ }^{1}$, SATORU MIYAZAKI ${ }^{1}$ and YASUNARI MANO ${ }^{1}$ \\ ${ }^{1}$ Faculty of Pharmaceutical Sciences, Tokyo University of Science, Chiba, Japan; \\ ${ }^{2}$ Department of Pharmacy, National Cancer Center Hospital, Tokyo, Japan
}

\begin{abstract}
Background/Aim: High-dose methotrexate is a therapy for acute leukemia, malignant lymphoma, and osteosarcoma. Glycyrrhizin has been used to treat hepatic dysfunction caused by high-dose methotrexate. However, few studies have investigated the interaction between glycyrrhizin and high-dose methotrexate. Materials and Methods: Male Wistar rats were treated with high-dose methotrexate (500 or $1,000 \mathrm{mg} / \mathrm{kg}$ ) alone, or with co-administration of $100 \mathrm{mg} / \mathrm{kg}$ glycyrrhizin. Plasma concentrations of methotrexate, alanine aminotransferase, aspartate aminotransferase, and total bilirubin were measured. Results: At both methotrexate doses, the blood concentration of methotrexate was significantly increased and total clearance was significantly reduced using co-administration of glycyrrhizin compared with methotrexate alone, which led to increased levels of hepatic enzymes. These results suggest that glycyrrhizin significantly increases the plasma level and delays the clearance of methotrexate, resulting in hepatic toxicity. Conclusion: The concomitant use of methotrexate and glycyrrhizin should be considered with caution.
\end{abstract}

Methotrexate is an antifolate drug that inhibits DNA synthesis and repair, and cellular replication (1, 2). High-dose methotrexate, defined as $500 \mathrm{mg} / \mathrm{m}^{2}$ or higher administered intravenously, is used for a variety of cancer types, such as acute lymphoblastic leukemia, lymphoma, and osteosarcoma

This article is freely accessible online.

Correspondence to: Yasunari Mano, Ph.D., 2641 Yamazaki, Noda, Chiba 278-8510, Japan. Tel: +81 4712136136, Fax: +81 471213636,e-mail: mano@rs.tus.ac.jp

Key Words: High-dose methotrexate (HD-MTX), glycyrrhizin, pharmacokinetic interactions, blood concentration, hepatic dysfunction, rat.
(3). However, high-dose methotrexate can cause a variety of toxic side-effects, including kidney injury, myelosuppression, mucositis, neurotoxicity and hepatotoxicity, which cause significant morbidity and delay treatment, leading to inferior anticancer outcomes (4). To prevent and mitigate toxicities, the serum concentrations of methotrexate and creatinine, and urine output are monitored, and supportive care is given, including intravenous hydration, urinary alkalinization, and rescue with leucovorin administration (5, 6). Recently, therapeutic drug monitoring has been implemented to reduce the side-effects of high-dose methotrexate by screening and managing its pharmacokinetics.

Hepatic toxicity has a high incidence during high-dose methotrexate treatment, causing elevation in the levels of hepatic transaminases such as serum alanine aminotransferase (ALT) and aspartate aminotransferase (AST) (7-9). To treat hepatic toxicity, an increased dose of leucovorin, along with glycyrrhizin, is often administered. Glycyrrhizin has antiinflammatory and anti-allergy effects (10) and is widely used in the treatment of liver diseases to improve liver function, as well as in the treatment of other conditions, such as pruritus and urticaria $(11,12)$.

However, few studies have investigated the interaction between glycyrrhizin and methotrexate. It is important to elucidate drug interactions that may influence the efficacy and safety of high-dose methotrexate therapy. In particular, we considered the need for a basic study to reflect the clinical use of high-dose methotrexate therapy. Therefore, we evaluated the pharmacokinetic interactions between highdose methotrexate and glycyrrhizin, reflecting the dosage and route of administration for clinical use in rats.

\section{Materials and Methods}

Chemicals. Acetonitrile, isoflurane, chloroform, and 0.5 M aqueous sodium hydroxide were purchased from FUJIFILM Wako Pure Chemical Corporation (Osaka, Japan). Methotrexate and glycyrrhizin 
were purchased from Tokyo Chemical Industry Co., Ltd. (Tokyo, Japan). Isotonic sodium chloride solution was purchased from Otsuka Pharmaceutical Co., Ltd. (Tokyo, Japan).

Animals and drug administration. Male Wistar rats (age, 9 weeks; mean body weight $=199.06 \mathrm{~g}$ ) were purchased from Sankyo Labo Service Co., Inc. (Tokyo, Japan) and fasted overnight prior to the experiment but were given ad libitum access to drinking water. In the preliminary experiment of this study, the minimum dose of methotrexate showing liver dysfunction in rats when administered in combination with glycyrrhizin was found to be $500 \mathrm{mg} / \mathrm{kg}$, therefore the doses of methotrexate used in this study were set at $500 \mathrm{mg} / \mathrm{kg}$ and $1,000 \mathrm{mg} / \mathrm{kg}$. Rats were divided into two groups: Methotrexateonly treatment group and methotrexate and glycyrrhizin co-treatment group, with four animals in each of the subgroups treated with 500 $\mathrm{mg} / \mathrm{kg}$ and $1,000 \mathrm{mg} / \mathrm{kg}$ methotrexate. Under isoflurane anesthesia, for the methotrexate-only treatment group, normal saline was administered intravenously rapidly at $2 \mathrm{ml} / \mathrm{kg}$ and methotrexate (500 or $1,000 \mathrm{mg} / \mathrm{kg}$ ) was administered intravenously for $10 \mathrm{~min}$ at 17.6 $\mathrm{ml} / \mathrm{kg}$. In the co-treatment group, $100 \mathrm{mg} / \mathrm{kg}$ glycyrrhizin was administered intravenously rapidly at $2 \mathrm{ml} / \mathrm{kg}$, and methotrexate at 500 or $1,000 \mathrm{mg} / \mathrm{kg}$ was administered intravenously as above for 10 min. The volume of administration solution was set to be the same for both groups. All animal experiments were conducted in compliance with the protocol reviewed by the Institutional Animal Care and Use Committee and approved by the President of the Tokyo University of Science (approval no. Y18066).

Blood sample collection. Blood (approximately $0.35 \mathrm{ml}$ ) was collected from the jugular vein at designated time intervals ( $1 \mathrm{~min}$, $30 \mathrm{~min}, 1 \mathrm{~h}, 4 \mathrm{~h}, 6 \mathrm{~h}$, and $8 \mathrm{~h}$ after methotrexate administration). Blood (approximately $0.80 \mathrm{ml}$ ) was also collected from the jugular vein at the time of liver function measurement $(5 \mathrm{~min}$ before and 4 , 6,8 , and $24 \mathrm{~h}$ after methotrexate administration). After centrifugation $\left(11,000 \times g\right.$ for $10 \mathrm{~min}$ at $\left.4^{\circ} \mathrm{C}\right)$ of the collected blood samples, plasma was collected and stored at $-30^{\circ} \mathrm{C}$ until analysis.

Analytical methods. Serum concentrations of methotrexate were determined by high-performance liquid chromatography as previously described, with slight modification (13). Plasma methotrexate $(150 \mu \mathrm{l})$ was supplemented with $300 \mu \mathrm{l}$ of acetonitrile. The samples were mixed for $30 \mathrm{~s}$ and centrifuged for $3 \mathrm{~min}$ at $11,000 \times g$ at $4^{\circ} \mathrm{C}$. Then $300 \mu \mathrm{l}$ of chloroform was added to the obtained supernatant $(350 \mu \mathrm{l})$ and the mixture was vortexed for 30 s. A volume of $50 \mu \mathrm{l}$ of supernatant was then subjected to highperformance liquid chromatographic analysis.

The separating column was a Poroshell 120 EC-C18 column [3.0×75 mm, $2.7 \mu \mathrm{m}$; Agilent Technologies, Inc. (Santa Clara, CA, USA)]. The mobile phase was $80 \mathrm{mM}$ acetate buffer $(\mathrm{pH}$ 4.0)/acetonitrile (88.8:11.2), and the column was run isocratically. The column temperature was $25^{\circ} \mathrm{C}$, the flow rate was $0.4 \mathrm{ml} / \mathrm{min}$, and the detection wavelength was set at $305 \mathrm{~nm}$. The limit of quantitation of methotrexate in rat serum was $0.2 \mu \mathrm{M}$.

Determination of hepatic data. Using the obtained plasma, measurements of hepatic parameters [AST, ALT, total bilirubin (TBil)] were conducted by SRL Co., Ltd. (Tokyo, Japan).

Data analysis. Serum methotrexate concentrations (C) were analyzed using a two-compartment open model. Pharmacokinetic parameters were obtained by linear regression analysis in a semilogarithmic data set and refer to the biexponential equation: $\mathrm{C}=\mathrm{Ae}^{-\alpha \mathrm{t}}+\mathrm{Be} \mathrm{e}^{-\beta \mathrm{t}}$. Total clearance $\left(\mathrm{CL}_{\mathrm{t}}\right)$ was calculated by the equation: $\mathrm{CL}_{\mathrm{t}}=\mathrm{Dose} /\left(\mathrm{AUC}_{0}+\mathrm{A} / \alpha+\mathrm{B} / \beta\right)$, where $\mathrm{AUC}_{0}$ is the area under the curve during drug infusion (10 $\mathrm{min})$, calculated using a triangular area, and $\mathrm{A}$ and $\mathrm{B}$ are the zero-time intercepts of the extrapolated lines of the $\alpha$ and $\beta$ phases, respectively. The central volume of distribution, $\mathrm{V}_{\mathrm{c}}$, was obtained by dividing the dose by $(\mathrm{A}+\mathrm{B})$, and the apparent volume of distribution in the postdistributional phase $\left(\mathrm{V}_{\beta}\right)$ was calculated by dividing $\mathrm{CL}_{\mathrm{t}}$ by $\beta$.

All results are expressed as the mean \pm standard deviation (S.D.). A comparison of parameters was performed using Student's $t$-test. Statistical significance was defined as $p<0.05$.

\section{Results}

Effect of glycyrrhizin on plasma concentration-time profiles of methotrexate in rats. To examine whether glycyrrhizin affects the pharmacokinetics of methotrexate, changes in the plasma concentration-time courses were assessed. The plasma concentration-time profiles of rats treated with 500 $\mathrm{mg} / \mathrm{kg}$ methotrexate alone and with $100 \mathrm{mg} / \mathrm{kg}$ glycyrrhizin are shown in Figure 1A, and the pharmacokinetic parameters are listed in Table I. As shown in Figure 1A, the plasma concentration of methotrexate at 1 and $4 \mathrm{~h}$ after administration was significantly higher (more than 10-fold) when co-administered with glycyrrhizin compared to the group treated with methotrexate only. Additionally, the $\mathrm{V}_{\beta}$ and $\mathrm{CL}_{t}$ values were significantly lower for the coadministration group than in the methotrexate-only group. The values of $t_{1 / 2 \alpha}$ for the co-administration group tended to be longer than for the methotrexate-only group but the difference was not statistically significant.

We further investigated the changes in plasma methotrexate level in rats administered a higher dose of methotrexate. The plasma concentration-time profiles under treatment with $1,000 \mathrm{mg} / \mathrm{kg}$ methotrexate alone and with 100 $\mathrm{mg} / \mathrm{kg}$ glycyrrhizin are shown in Figure $1 \mathrm{~B}$, and the pharmacokinetic parameters are listed in Table II. As shown in Figure 1B, the plasma concentration of methotrexate at 1$6 \mathrm{~h}$ after administration was significantly higher when coadministered with $100 \mathrm{mg} / \mathrm{kg}$ glycyrrhizin compared to the methotrexate-only group. Additionally, the values of $\mathrm{CL}_{\mathrm{t}}$ for the co-administration group were significantly reduced compared to those for the group treated with methotrexate only, and the value of $\mathrm{AUC}_{\infty}$ for the co-administration group was significantly increased compared to the methotrexateonly group.

Effect of co-administration of glycyrrhizin and methotrexate on hepatic data of rats. The changes in hepatic data for the methotrexate-only groups and co-administration groups are shown for levels of AST (Figure 2), ALT (Figure 3), and TBil (Figure 4). 



Figure 1. Plasma concentration-time curve of methotrexate (MTX) in rats after intravenous administration of MTX at $500 \mathrm{mg} / \mathrm{kg}$ (A) and 1,000 $\mathrm{mg} / \mathrm{kg}(B)$ alone and in co-administration with $100 \mathrm{mg} / \mathrm{kg}$ glycyrrhizin (GZ). Each data point represents the mean \pm S.D. of four rats. Significantly different at $* p<0.05$ vs. MTX alone.

Table I. Pharmacokinetic parameters of methotrexate (MTX) after intravenous administration at $500 \mathrm{mg} / \mathrm{kg}$ alone and in combination with $100 \mathrm{mg} / \mathrm{kg}$ glycyrrhizin (GZ).

\begin{tabular}{lccc}
\hline Parameter & MTX only & MTX+GZ & $p$-Value \\
\hline $\mathrm{C}_{0}, \mu \mathrm{M}$ & $2,229 \pm 477$ & $1,768 \pm 393$ & 0.19 \\
$\mathrm{~V}_{\mathrm{c}}, \mathrm{ml} / \mathrm{kg}$ & $510 \pm 105$ & $646 \pm 146$ & 0.19 \\
$\mathrm{~V}_{\beta}, \mathrm{ml} / \mathrm{kg}$ & $2,130 \pm 225$ & $998 \pm 404$ & $\mathbf{0 . 0 1}$ \\
$\mathrm{V}_{\mathrm{ss}}, \mathrm{ml} / \mathrm{kg}$ & $751 \pm 109$ & $867 \pm 317$ & 0.53 \\
$\mathrm{t}_{1 / 2 \alpha}, \mathrm{min}$ & $12 \pm 1.6$ & $23 \pm 21.1$ & 0.37 \\
$\mathrm{t}_{1 / 2 \beta}, \mathrm{min}$ & $58 \pm 3$ & $52 \pm 4$ & 0.08 \\
$\mathrm{CL}_{\mathrm{t}}, \mathrm{ml} / \mathrm{min} \cdot \mathrm{kg}$ & $26 \pm 3.32$ & $13.1 \pm 4.5$ & $\mathbf{0 . 0 1}$ \\
$\mathrm{AUC}_{\infty}, \mu \mathrm{g} \cdot \mathrm{h} / \mathrm{ml}$ & $330 \pm 49$ & $711 \pm 298$ & 0.08 \\
\hline
\end{tabular}

$\mathrm{AUC}_{\infty}$ : Area under the concentration-time curve at infinity; $\mathrm{C}_{0}$ : drug concentration at time $0 ; \mathrm{CL}_{\mathrm{t}}$ : total clearance; $\mathrm{t}_{1 / 2 \alpha} / \mathrm{t}_{1 / 2 \beta}$ : terminal halflife of $\alpha$ phase $/ \beta$ phase; $\mathrm{V}_{\mathrm{c}}$ : volume of the central compartment or the initial volume of distribution; $\mathrm{V}_{\mathrm{ss}}$ : steady-state volume of distribution; $\mathrm{V}_{\beta}$ : apparent volume of distribution in the post-distributional phase Each point represents the mean \pm S.D. of four rats. Statistically significant $p$-values are shown in bold.

At $500 \mathrm{mg} / \mathrm{kg}$ methotrexate, the mean AST level was significantly increased at 4,6 and $8 \mathrm{~h}$; the ALT level was significantly increased at 4, 6, 8 and $24 \mathrm{~h}$; and the T-bil level was significantly increased at 4 and $6 \mathrm{~h}$ after administration in the co-administration group compared with the single administration group. At $1,000 \mathrm{mg} / \mathrm{kg}$ methotrexate, the combination significantly increased the level of AST at 6 and $8 \mathrm{~h}$; of ALT at 4, 6 and $8 \mathrm{~h}$; and T-bil at 4 and $24 \mathrm{~h}$ after administration.
Table II. Pharmacokinetic parameters of methotrexate (MTX) after intravenous administration at 1,000 $\mathrm{mg} / \mathrm{kg}$ alone and in combination with $100 \mathrm{mg} / \mathrm{kg}$ glycyrrhizin (GZ).

\begin{tabular}{lccc}
\hline Parameter & MTX only & MTX+GZ & $p$-Value \\
\hline $\mathrm{C}_{0}, \mu \mathrm{M}$ & $5,341 \pm 1,578$ & $5,100 \pm 1,486$ & 0.83 \\
$\mathrm{~V}_{\mathrm{c}}, \mathrm{ml} / \mathrm{kg}$ & $449 \pm 171$ & $468 \pm 169$ & 0.88 \\
$\mathrm{~V}_{\beta}, \mathrm{ml} / \mathrm{kg}$ & $1,336 \pm 91$ & $1,597 \pm 577$ & 0.44 \\
$\mathrm{~V}_{\mathrm{ss}}, \mathrm{ml} / \mathrm{kg}$ & $625 \pm 143$ & $1,130 \pm 375$ & 0.07 \\
$\mathrm{t}_{1 / 2 \alpha}, \mathrm{min}$ & $12.2 \pm 3.8$ & $12.5 \pm 5.5$ & 0.91 \\
$\mathrm{t}_{1 / 2 \beta}, \mathrm{min}$ & $46 \pm 4$ & $95 \pm 34.8$ & 0.06 \\
$\mathrm{CL}_{\mathrm{t}}, \mathrm{ml} / \mathrm{min} \cdot \mathrm{kg}$ & $20 \pm 1.3$ & $12 \pm 0.4$ & $\mathbf{< 0 . 0 1}$ \\
$\mathrm{AUC}_{\infty}, \mu \mathrm{g} \cdot \mathrm{h} / \mathrm{ml}$ & $826 \pm 52$ & $1437 \pm 54$ & $\mathbf{< 0 . 0 1}$
\end{tabular}

$\mathrm{AUC}_{\infty}$ : Area under the concentration-time curve at infinity; $\mathrm{C}_{0}$ : drug concentration at time $0 ; \mathrm{CL}_{\mathrm{t}}$ : total clearance; $\mathrm{t}_{1 / 2 \alpha} / \mathrm{t}_{1 / 2 \beta}$ : terminal halflife of $\alpha$ phase $/ \beta$ phase; $\mathrm{V}_{\mathrm{c}}$ : volume of the central compartment or the initial volume of distribution; $\mathrm{V}_{\mathrm{ss}}$ : steady-state volume of distribution; $\mathrm{V}_{\beta}$ : apparent volume of distribution in the post-distributional phase; Each point represents the mean \pm S.D. of four rats. Statistically significant $p$-values are shown in bold.

At both doses, increases in AST, ALT, and T-bil levels were observed at approximately the same time as increases in serum methotrexate levels in the co-administration groups. In addition, at $1,000 \mathrm{mg} / \mathrm{kg}$, the AST, ALT and T-bil levels in the co-administration groups were increased by approximately 2.5-fold, approximately 2-fold, and approximately 1.5 -fold, respectively, compared with those with administration at $500 \mathrm{mg} / \mathrm{kg}$ methotrexate. 

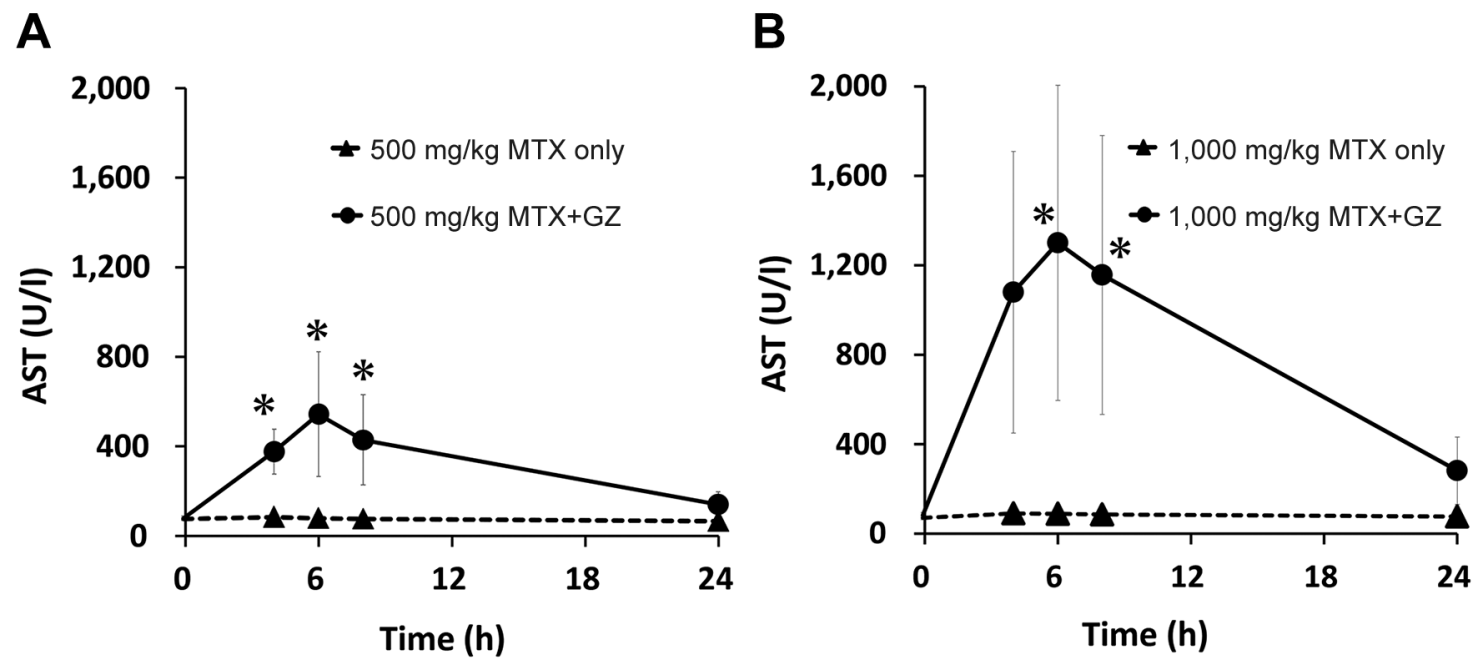

Figure 2. Plasma concentration-time profiles of aspartate aminotransferase (AST) in rats after intravenous administration of MTX at $500 \mathrm{mg} / \mathrm{kg}$ (A) and $1,000 \mathrm{mg} / \mathrm{kg}(B)$ alone and in co-administration with $100 \mathrm{mg} / \mathrm{kg}$ glycyrrhizin (GZ). Each point represents the mean \pm S.D. of four rats. Significantly different at $* p<0.05 v s$. MTX alone.

A



B



Figure 3. Plasma concentration-time profiles of alanine aminotransferase (ALT) in rats after intravenous administration of MTX at $500 \mathrm{mg} / \mathrm{kg}(A)$ and $1,000 \mathrm{mg} / \mathrm{kg}(B)$ alone and in co-administration with $100 \mathrm{mg} / \mathrm{kg}$ glycyrrhizin (GZ). Each point represents the mean $\pm S . D$. of four rats. Significantly different at $* p<0.05 v s$. MTX alone.

\section{Discussion}

To examine whether glycyrrhizin affects the pharmacokinetics of methotrexate, we evaluated the pharmacokinetic interactions between methotrexate and glycyrrhizin. High-dose methotrexate and glycyrrhizin were administered intravenously to rats in a manner reflecting the dosage and route of administration in the clinic. In this study, we showed that co-administration of glycyrrhizin and methotrexate (500 $\mathrm{mg} / \mathrm{kg}$ ) significantly reduced the $\mathrm{V}_{\beta}$ and $\mathrm{CL}_{\mathrm{t}}$ values, and co- administration at $1,000 \mathrm{mg} / \mathrm{kg}$ methotrexate significantly reduced $\mathrm{CL}_{\mathrm{t}}$ and significantly increased the value of $\mathrm{AUC}_{\infty}$ compared to MTX alone. These results suggest that glycyrrhizin indeed affects the pharmacokinetics of methotrexate and delays methotrexate excretion. In addition, increases in the hepatic markers AST, ALT and T-bil were observed at approximately the same time as increases in serum methotrexate levels after co-administration of glycyrrhizin and methotrexate. It was suggested that glycyrrhizin, which was originally administered to improve liver function, may 

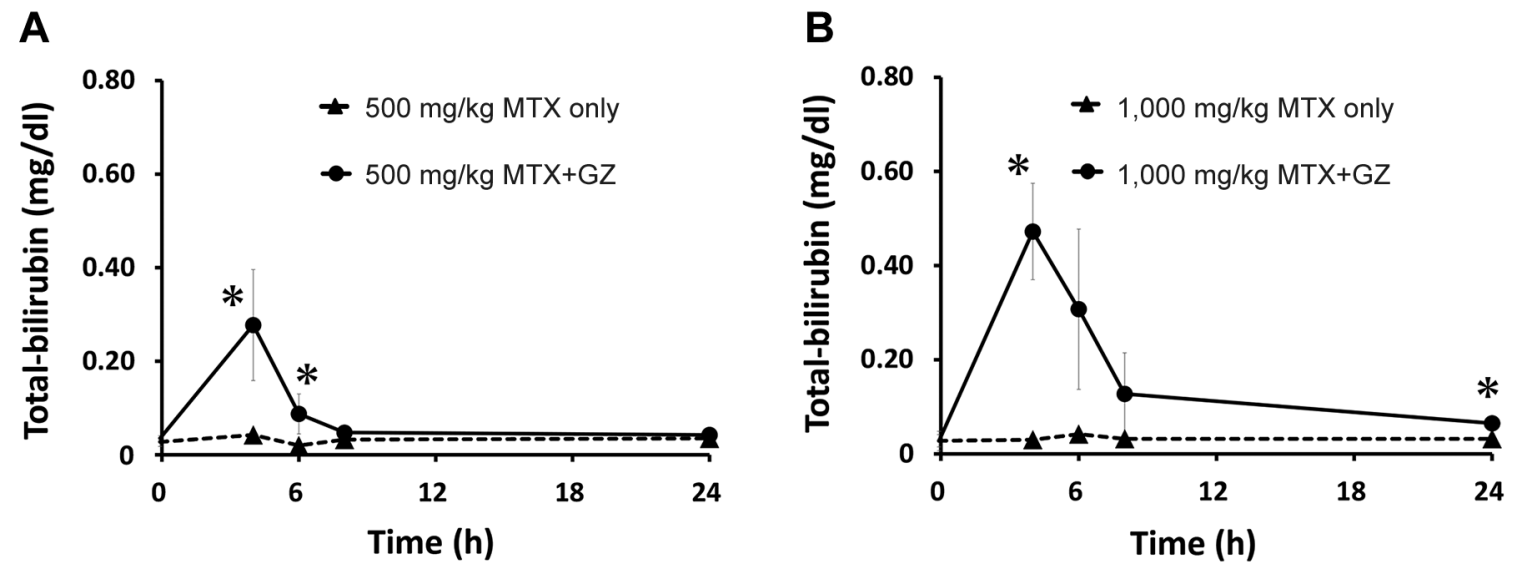

Figure 4. Plasma concentration-time profiles of total bilirubin in rats after intravenous administration of MTX at $500 \mathrm{mg} / \mathrm{kg}$ (A) and 1,000 mg/kg (B) alone and in co-administration with $100 \mathrm{mg} / \mathrm{kg}$ glycyrrhizin $(\mathrm{GZ})$. Each point represents the mean \pm S.D. of four rats. Significantly different at $* p<0.05$ vs. MTX alone.

exacerbate liver damage. To the best of our knowledge, this is the first study to demonstrate an interaction between methotrexate and glycyrrhizin in rats to reflect the clinical use of high-dose methotrexate therapy.

We found that glycyrrhizin affected the pharmacokinetics of methotrexate and delayed methotrexate excretion. These results are consistent with a previous study showing that systemic exposure and mean residence time of methotrexate were increased by oral administration of glycyrrhizin and methotrexate (14). However, in that report, the dosage was $5 \mathrm{mg} / \mathrm{kg}$ methotrexate, and the route of administration was oral, assuming a low dose of methotrexate (5-25 mg/week) as in clinical use for rheumatoid arthritis $(15,16)$. High-dose methotrexate was $8-12 \mathrm{~g} / \mathrm{m}^{2}(17-20)$; in other words, the dose of methotrexate was $100-300 \mathrm{mg} / \mathrm{kg}$ per week in patients with osteosarcoma and $30-100 \mathrm{mg} / \mathrm{kg}$ per week in patients with lymphoma and leukemia. In our study, the doses of methotrexate $(1,000 \mathrm{mg} / \mathrm{kg})$ and glycyrrhizin $(100$ $\mathrm{mg} / \mathrm{kg}$ ) administered to rats correspond to the clinical doses $(21,22)$. In addition, the dose administered to rats was calculated using the allometric formula (23), which converts doses between humans and rats. Using this formula, a human methotrexate dose of $100-300 \mathrm{mg} / \mathrm{kg}$ is equivalent to a rat dose of $620-1,860 \mathrm{mg} / \mathrm{kg}$. The high methotrexate dose $(1,000$ $\mathrm{mg} / \mathrm{kg}$ ) we administered to rats falls within the calculated dose range for high-dose methotrexate therapy in humans. Similarly, a human methotrexate dose of $30-100 \mathrm{mg} / \mathrm{kg}$ is equivalent to a rat dose of $186-620 \mathrm{mg} / \mathrm{kg}$. The lower methotrexate dose $(500 \mathrm{mg} / \mathrm{kg})$ we administered to rats was included in this calculated dose range. Therefore, the dose used in our study reflects the clinical use of high-dose methotrexate in therapy for osteosarcoma, lymphoma, and leukemia. In addition, a retrospective study using medical records showed that concomitant use of the glycyrrhizincontaining preparation Stronger Neo-Minophagen $\mathrm{C}$ might be related to delayed elimination of plasma methotrexate in high-dose methotrexate therapy (24). Our pharmacokinetic interaction results support those findings.

The plasma methotrexate level was elevated with the concomitant use of glycyrrhizin. Methotrexate is poorly metabolized in the liver, and the main route of excretion is via the renal system and, to a small extent, in the bile. It has been reported that multiple transporters, including organic anion transporter 3, ATP-binding cassette subfamily G member 2 (ABCG2, formerly BCRP1) and ABCC2 (formerly, MRP2), are implicated in the excretion of methotrexate $(25,26)$. The biliary excretion rate of methotrexate under high-dose therapy is $7 \%$ via ABCC2, which is involved in biliary excretion (27). Glycyrrhizin has been reported to inhibit $\mathrm{ABCC} 2$ (14), which might result in competitive inhibition of methotrexate elimination. Based on these findings, it was suggested that biliary excretion is reduced with increasing doses of methotrexate, and the interaction with glycyrrhizin appeared to be remarkable. In addition, glycyrrhizic acid, a metabolite of glycyrrhizin, has been reported to inhibit ABCG2 and ABCC2 (14). Therefore, we consider that both glycyrrhizin and glycyrrhizic acid may inhibit the biliary excretion of methotrexate, thus enhancing its toxicity.

An increase in hepatic markers, such as AST, ALT, and T-bil, was observed at approximately the same time as increases in blood methotrexate levels in the concomitant use of methotrexate and glycyrrhizin. The co-administration of these agents led to a decrease in the value of $\mathrm{CL}_{t}$ and an increase in the value of $\mathrm{AUC}_{\infty}$ of methotrexate, resulting in increased systemic exposure and mean residence time of methotrexate, 
possibly enhancing hepatic toxicity. High methotrexate concentrations have been associated with an increased risk of toxicity (28). Methotrexate-induced liver toxicity with increased AST and ALT levels correlated with AUC has been reported (29). Previous studies correlated methotrexate exposure with hepatotoxicity $(30,31)$. Our study showed AST, ALT, and T-bil levels in the group administered $1,000 \mathrm{mg} / \mathrm{kg}$ methotrexate and glycyrrhizin were increased by approximately 2.5-, 2-, and 1.5fold respectively, compared with $500 \mathrm{mg} / \mathrm{kg}$ methotrexate coadministration. These results suggest that methotrexate exposure is involved in liver enzyme elevation, which is consistent with the results of previous studies. In the present study, we investigated the concentration and pharmacokinetic parameters of methotrexate for up to $8 \mathrm{~h}$; however, hepatic data were collected for up to $24 \mathrm{~h}$. Interestingly, liver enzyme elevation was transient and reversible. These results are consistent with many cases in clinical practice, where such laboratory findings resolve with a modification or discontinuation of the dose and do not lead to chronic liver disease $(32,33)$.

In conclusion, we found that co-administration of highdose methotrexate and glycyrrhizin significantly increased the plasma methotrexate level and delayed methotrexate clearance, which resulted in hepatic toxicity due to elevated liver enzyme levels in rats. Given our pharmacokinetic interaction findings, the concomitant use of methotrexate and glycyrrhizin should be performed with caution.

\section{Conflicts of Interest}

The Authors declare that they have no competing interests in relation to this study.

\section{Authors' Contributions}

K.A., T.H., and M.T. performed the experiments; K.A., T.H. M.T., and Y. M. conceived the study; K.A., T.H., and S.M conducted statistical analysis; K.A and Y.M drafted the article; T.H., M.T., A.M.-M., Y. K., S.M., and Y.M. contributed to the discussion and review of the final article; all Authors approved the final article.

\section{References}

1 Goldman ID and Matherly LH: The cellular pharmacology of methotrexate. Pharmacol Ther 28(1): 77-102, 1985. PMID: 2414788. DOI: $10.1016 / 0163-7258(85) 90083-\mathrm{x}$

2 Hagner $\mathrm{N}$ and Joerger M: Cancer chemotherapy: targeting folic acid synthesis. Cancer Manag Res 2: 293-301, 2010. PMID: 21301589. DOI: $10.2147 / C M R . S 10043$

3 Ackland SP and Schilsky RL: High-dose methotrexate: a critical reappraisal. J Clin Oncol 5(12): 2017-2031, 1987. PMID: 3316519. DOI: 10.1200/JCO.1987.5.12.2017

4 Howard SC, McCormick J, Pui CH, Buddington RK and Harvey RD: Preventing and managing toxicities of high-dose methotrexate. Oncologist 21(12): 1471-1482, 2016. PMID: 27496039. DOI: $10.1634 /$ theoncologist.2015-0164
5 Treon SP and Chabner BA: Concepts in use of high-dose methotrexate therapy. Clin Chem 42(8 Pt 2): 1322-1329, 1996. PMID: 8697606

6 Christensen ML, Rivera GK, Crom WR, Hancock ML and Evans WE: Effect of hydration on methotrexate plasma concentrations in children with acute lymphocytic leukemia. J Clin Oncol 6(5): 797-801, 1988. PMID: 3163362. DOI: 10.1200/ JCO.1988.6.5.797

7 Rask C, Albertioni F, Bentzen SM, Schroeder H and Peterson C: Clinical and pharmacokinetic risk factors for high-dose methotrexate-induced toxicity in children with acute lymphoblastic leukemia-a logistic regression analysis. Acta Oncol 37(3): 277284, 1998. PMID: 9677100 . DOI: 10.1080/028418698429586

8 Holmboe L, Andersen AM, Mørkrid L, Slørdal L and Hall KS: High dose methotrexate chemotherapy: pharmacokinetics, folate and toxicity in osteosarcoma patients. Br J Clin Pharmacol 73(1): 106-114, 2012. PMID: 21707700. DOI: 10.1111/j.13652125.2011.04054.x

9 Cheng KK: Association of plasma methotrexate, neutropenia, hepatic dysfunction, nausea/vomiting and oral mucositis in children with cancer. Eur J Cancer Care (Engl) 17(3): 306-311, 2008. PMID: 18419635. DOI: 10.1111/j.1365-2354.2007. 00843.x

10 Li JY, Cao HY, Liu P, Cheng GH and Sun MY: Glycyrrhizic acid in the treatment of liver diseases: literature review. Biomed Res Int 2014: 872139, 2014. PMID: 24963489. DOI: 10.1155/ 2014/872139

11 Kiso Y, Tohkin M, Hikino H, Hattori M, Sakamoto T and Namba $\mathrm{T}$ : Mechanism of antihepatotoxic activity of glycyrrhizin. I: Effect on free radical generation and lipid peroxidation. Planta Med 50(4): 298-302, 1984. PMID: 6505079. DOI: 10.1055/s2007-969714

12 Deng S, May BH, Zhang AL, Lu C and Xue CC: Topical herbal medicine combined with pharmacotherapy for psoriasis: a systematic review and meta-analysis. Arch Dermatol Res 305(3): 179-189, 2013. PMID: 23354931. DOI: 10.1007/s00403-013-1316-y

13 Montemurro M, De Zan MM and Robles JC: Optimized high performance liquid chromatography-ultraviolet detection method using core-shell particles for the therapeutic monitoring of methotrexate. J Pharm Anal 6(2): 103-111, 2016. PMID: 29403969. DOI: 10.1016/j.jpha.2015.12.001

14 Lin SP, Tsai SY, Hou YC and Chao PD: Glycyrrhizin and licorice significantly affect the pharmacokinetics of methotrexate in rats. J Agric Food Chem 57(5): 1854-1859, 2009. PMID: 19209930. DOI: $10.1021 /$ jf8029918

15 Cegieła U, Sliwiński L, Kaczmarczyk-Sedlak I and Folwarczna $\mathrm{J}$ : In vivo effects of high-dose methotrexate on bone remodeling in rats. Pharmacol Rep 57(4): 504-514, 2005. PMID: 16129918.

16 De S, Kundu S, Chatterjee U, Chattopadhyay S and Chatterjee M: Allylpyrocatechol attenuates methotrexate-induced hepatotoxicity in a collagen-induced model of arthritis. Free Radic Res 52(6): 698-711, 2018. PMID: 29661087. DOI: 10.1080/10715762.2018.1466391

17 Souhami RL, Craft AW, Van der Eijken JW, Nooij M, Spooner D, Bramwell VH, Wierzbicki R, Malcolm AJ, Kirkpatrick A, Uscinska BM, Van Glabbeke M and Machin D: Randomised trial of two regimens of chemotherapy in operable osteosarcoma: a study of the European Osteosarcoma Intergroup. Lancet 350(9082): 911-917, 1997. PMID: 9314869. DOI: 10.1016/ S0140-6736(97)02307-6 
18 Bacci G, Ferrari S, Bertoni F, Ruggieri P, Picci P, Longhi A Casadei R, Fabbri N, Forni C, Versari M and Campanacci M: Long-term outcome for patients with nonmetastatic osteosarcoma of the extremity treated at the istituto ortopedico rizzoli according to the istituto ortopedico rizzoli/osteosarcoma2 protocol: an updated report. J Clin Oncol 18(24): 4016-4027, 2000. PMID: 11118462. DOI: 10.1200/JCO.2000.18.24.4016

19 Winkler K, Beron G, Delling G, Heise U, Kabisch H, Purfürst C, Berger J, Ritter J, Jürgens H and Gerein V: Neoadjuvant chemotherapy of osteosarcoma: results of a randomized cooperative trial (COSS-82) with salvage chemotherapy based on histological tumor response. J Clin Oncol 6(2): 329-337, 1988. PMID: 2448428. DOI: 10.1200/JCO.1988.6.2.329

20 Marina NM, Smeland S, Bielack SS, Bernstein M, Jovic G, Krailo MD, Hook JM, Arndt C, van den Berg H, Brennan B, Brichard B, Brown KLB, Butterfass-Bahloul T, Calaminus G, Daldrup-Link HE, Eriksson M, Gebhardt MC, Gelderblom H, Gerss J, Goldsby R, Goorin A, Gorlick R, Grier HE, Hale JP, Hall KS, Hardes J, Hawkins DS, Helmke K, Hogendoorn PCW, Isakoff MS, Janeway KA, Jürgens H, Kager L, Kühne T, Lau CC, Leavey PJ, Lessnick SL, Mascarenhas L, Meyers PA, Mottl H, Nathrath M, Papai Z, Randall RL, Reichardt P, Renard M, Safwat AA, Schwartz CL, Stevens MCG, Strauss SJ, Teot L, Werner M, Sydes MR and Whelan JS: Comparison of MAPIE versus MAP in patients with a poor response to preoperative chemotherapy for newly diagnosed high-grade osteosarcoma (EURAMOS-1): an open-label, international, randomised controlled trial. Lancet Oncol 17(10): 1396-1408, 2016. PMID: 27569442. DOI: $10.1016 / \mathrm{S} 1470-2045$ (16)30214-5

21 Bremnes RM, Slørdal L, Wist E and Aarbakke J: Dosedependent pharmacokinetics of methotrexate and 7 hydroxymethotrexate in the rat in vivo. Cancer Res 49(22): 6359-6364, 1989. PMID: 2804982.

22 Wang Z, Okamoto M, Kurosaki Y, Nakayama T and Kimura T: Pharmacokinetics of glycyrrhizin in rats with D-galactosamineinduced hepatic disease. Biol Pharm Bull 19(6): 901-904, 1996. PMID: 8799498. DOI: 10.1248/bpb.19.901

23 Nair $A B$ and Jacob S: A simple practice guide for dose conversion between animals and human. J Basic Clin Pharm 7(2): 27-31, 2016. PMID: 27057123. DOI: 10.4103/09760105.177703

24 Ishizaki J, Nakano C, Kitagawa K, Suga Y and Sai Y: A previously unknown drug-drug interaction is suspected in delayed elimination of plasma methotrexate in high-dose methotrexate therapy. Ann Pharmacother 54(1): 29-35, 2020. PMID: 31416331. DOI: 10.1177/1060028019870445

25 VanWert AL and Sweet DH: Impaired clearance of methotrexate in organic anion transporter 3 (Slc22a8) knockout mice: a gender specific impact of reduced folates. Pharm Res 25(2): 453-462, 2008. PMID: 17660957. DOI: 10.1007/s11095-007-9407-0
26 Vlaming ML, Pala Z, van Esch A, Wagenaar E, de Waart DR, van de Wetering K, van der Kruijssen CM, Oude Elferink RP, van Tellingen $\mathrm{O}$ and Schinkel AH: Functionally overlapping roles of Abcg2 (Bcrp1) and Abcc2 (Mrp2) in the elimination of methotrexate and its main toxic metabolite 7hydroxymethotrexate in vivo. Clin Cancer Res 15(9): 3084-3093, 2009. PMID: 19383815. DOI: 10.1158/1078-0432.CCR-08-2940

27 Madden T and Eaton VE: Methotrexate. In: Therapeutic Drug Monitoring. Schumacher GE (eds.). Connecticut, Appleton \& Lange, pp. 527-552, 1995.

28 Abelson HT, Fosburg MT, Beardsley GP, Goorin AM, Gorka C, Link $M$ and Link D: Methotrexate-induced renal impairment: clinical studies and rescue from systemic toxicity with high-dose leucovorin and thymidine. J Clin Oncol 1(3): 208-216, 1983. PMID: 6607976. DOI: 10.1200/JCO.1983.1.3.208

29 Exadaktylos P, Reiss T, Schobess R, Hommann M, Höhne S and Beck A: [Acute hepatotoxicity with intermediate-dose methotrexate in children with leukemia and non-Hodgkin's lymphoma]. Klin Padiatr 206(4): 315-318, 1994. PMID: 7967431. DOI: $10.1055 / \mathrm{s}-2008-1046622$

30 Hegyi M, Gulácsi A, Cságoly E, Csordás K, Eipel OT, Erdélyi DJ, Müller J, Nemes K, Lautner-Csorba $\mathrm{O}$ and Kovács GT: Clinical relations of methotrexate pharmacokinetics in the treatment for pediatric osteosarcoma. J Cancer Res Clin Oncol 138(10): 1697-1702, 2012. PMID: 22652833. DOI: 10.1007/ s00432-012-1214-2

31 Joerger M, Huitema AD, Krähenbühl S, Schellens JH, Cerny T, Reni M, Zucca E, Cavalli F and Ferreri AJ: Methotrexate area under the curve is an important outcome predictor in patients with primary CNS lymphoma: A pharmacokineticpharmacodynamic analysis from the IELSG no. 20 trial. Br J Cancer 102(4): 673-677, 2010. PMID: 20125159. DOI: 10.1038/ sj.bjc. 6605559

32 Bath RK, Brar NK, Forouhar FA and Wu GY: A review of methotrexate-associated hepatotoxicity. J Dig Dis 15(10): 517524, 2014. PMID: 25139707. DOI: 10.1111/1751-2980.12184

33 Weber BL, Tanyer G, Poplack DG, Reaman GH, Feusner JH, Miser JS and Bleyer WA: Transient acute hepatotoxicity of highdose methotrexate therapy during childhood. NCI Monogr (5): 207-212, 1987. PMID: 3481038.
Received April 18, 2021

Revised May 23, 2021

Accepted May 26, 2021 